\title{
Adhesion of benzocyclobutene-passivated silicon in epoxy layered structures
}

\author{
Robert J. Hohlfelder, ${ }^{\text {a) }}$ Daniel A. Maidenberg, and Reinhold H. Dauskardt ${ }^{\text {b) }}$ \\ Department of Materials Science and Engineering, Stanford University, \\ Stanford, California 94305-2205 \\ Yueguang Wei and John W. Hutchinson \\ Division of Engineering and Applied Sciences, Harvard University, Cambridge, Massachusetts 02138
}

(Received 6 April 2000; accepted 10 October 2000)

\begin{abstract}
Adhesion and subcritical debonding at interfaces between a silica-filled epoxy underfill and a silicon die passivated by silicon nitride and benzocyclobutene (BCB) layers were investigated. Adhesion was measured in terms of a critical value of the applied strain energy release rate, $G\left(\mathrm{~J} / \mathrm{m}^{2}\right)$. Subcritical debond-growth rates in the range of $10^{-9}$ to $10^{-3} \mathrm{~m} / \mathrm{s}$ were characterized as a function of applied $G$. Adhesion and subcritical debonding were affected by changes in interfacial chemistry and environment. The surprisingly large effect of adjacent layer elastic properties on interfacial adhesion was demonstrated with simulations of interfacial fracture using a mechanics of materials approach. Interfacial chemistry was modified by using different adhesion promoters, by varying the $\mathrm{BCB}$ cure state, and by using different epoxy underfill resins. The effects of environmental variables were studied with temperature- and humidity-controlled environments in order to determine the separate roles of moisture activity and temperature.
\end{abstract}

\section{INTRODUCTION}

Demands for faster performance and higher I/O counts for integrated circuits require commensurate increases in the density and complexity of package interconnect structures. Traditional packages are being supplanted by flip-chip solder ball array packages in which the IC and substrate are connected face-to-face through an array of metallized bond pads and solder balls. Such structures contain a number of passivation and solder mask layers together with a polymer underfill intended to assist in thermal management and provide protection from moisture and other environmental species. The underfill is typically an epoxy resin with thermal expansion and elastic properties tailored by the addition of micron-sized silica beads.

During fabrication and in use, high thermal expansion mismatch and polymer curing strains may be generated in the packages. The resulting residual stresses must be accommodated by the solder ball array and the layered underfill region. Failure of the package involving delamination of interfaces in the underfill region and metallized bond pads together with cracking of the adjacent mate-

${ }^{a)}$ Currently at Sandia National Laboratories, Albuquerque, NM 87185-1415.

b) Address all correspondence to this author.

e-mail: dauskardt@stanford.edu rials and solder balls is frequently encountered and poses significant challenges for current flip-chip technologies. ${ }^{1-3}$ Delaminations may permit moisture to penetrate into the package initiating corrosive processes in the metallized interconnections as well as increasing the residual and thermomechanical stresses carried by the solder balls.

A critical issue in determining overall package reliability is therefore the resistance of interfaces within the package to the initiation and growth of interfacial delaminations. Current accelerated reliability tests which involve subjecting entire packages to thermal and environmental stresses provide little insight into the physical processes controlling adhesion and no quantitative basis for assessing the effects of new materials or interface chemistries. ${ }^{4}$ Traditional mechanics methods for measuring interfacial adhesion in layered structures such as the scratch, peel, and stud pull tests suffer from a number of limitations including the propensity for plastically deforming the films and relaxation of residual film stresses, both of which lead to a lack of repeatability and interpretability. ${ }^{5}$ Classical thermodynamic approaches that relate the work of adhesion to interface surface energies using contact angle and contact mechanics measurements may produce adhesion values that are orders of magnitude less than the actual energy required to separate the interface. ${ }^{6}$ These measurements therefore do not account for additional energy dissipation processes such as plas- 
ticity in adjacent ductile layers. In fact, they might be fundamentally limited by surface relaxation processes and environmental contamination which significantly lower the measured surface energy.

In recent years, it has been recognized that interfacial delamination can be studied using the methodologies of fracture mechanics, modeling delamination as a crack propagating along the interface between two materials (see e.g., Refs. 7 and 8). The mechanics of fracture at interfaces and in layered materials is well-developed and application of these principles to thin film microelectronic interconnects has proven to be quantitative and repeatable. ${ }^{5,9-12}$ Similar techniques have been applied successfully to systems containing polymer layers., ${ }^{2,13-18}$ Comparatively little work has been undertaken to quantitatively investigate the effects of environmental variables, such as temperature and humidity, on the kinetics of interfacial debond growth. However, work on environmentally-assisted crack growth in similar bulk materials ${ }^{19-23}$ and subcritical debonding in thin film interconnect structures ${ }^{5,10,15,24}$ suggests that the phenomena may be relevant to long-term reliability. In particular, kinetic models relating crack growth to temperature, environmental species, and interfacial chemical bonding may be applicable to the growth of interfacial delaminations.

Accordingly, in this work we investigate adhesion and subcritical debonding at interfaces between a silica-filled epoxy underfill and a silicon die passivated by silicon nitride and benzocyclobutene (BCB) layers. $\mathrm{BCB}$ is a photodefinable, low dielectric constant polymer developed for packaging and interconnect applications. ${ }^{25}$ The integrity of the interface between underfill and silicon passivated by new materials like $\mathrm{BCB}$ is an important determinant of package reliability. Adhesion was studied using previously reported methods in which the interface fracture energy was measured in terms of a critical value of the applied strain energy release rate, $G\left(\mathrm{~J} / \mathrm{m}^{2}\right){ }^{5,8,9}$ Subcritical debond growth-rate behavior was characterized using similar procedures. ${ }^{2,5,10} \mathrm{We}$ were particularly interested in examining how adhesion and debond growth rates were affected by changes in interfacial chemistry and environment. Interfacial chemistry was modified by using different adhesion promoters, by varying the BCB cure state, and by using different epoxy underfill resins. The effects of environmental variables on debond growth were studied by performing experiments within a temperature- and humidity-controlled environmental chamber.

\section{EXPERIMENTAL PROCEDURES}

\section{A. Specimen preparation}

Fracture mechanics based specimen configurations containing the underfill region and associated passivation layers sandwiched between silicon substrates were pre- pared for study. The underfill and passivation layer thicknesses were chosen to approximate dimensions encountered in flip-chip packages. Passivated silicon substrates were prepared from 200-mm-diameter wafers coated with $250 \mathrm{~nm}$ of low pressure chemical vapor deposition (LPCVD) nitride prior to spin coating and curing of a $5-\mu \mathrm{m}$-thick $\mathrm{BCB}$ resin layer. The BCB resins are modified prepolymers of DVS-bisBCB and supplied as solutions of B-staged monomers in mesitylene. ${ }^{25}$

The effects of two silane adhesion promoters at the nitride to $\mathrm{BCB}$ interface were examined by first depositing the coupling agent on the nitride surface from a dilute solution. Standard spin coating procedures involving a $500 \mathrm{rpm}$ spread cycle followed by a $30 \mathrm{~s}$ spin at $3000 \mathrm{rpm}$ for solvent drying were employed. The commercially available adhesion promoters, AP3000 and AP8000 (Dow Chemical, Midland, MI), employed conventional silane chemistry with different reactive functional end groups and relatively short linear chains with $n=2-3$ carbon repeat units (Fig. 4). The AP8000 was cast from a $0.1 \%$ solution of (3-aminopropyl)triethoxysilane (APS) in 1-methoxy-2-propanol as a solvent and uses an amine end group, while the AP3000 consisted of a $0.3 \%$ vinyltriacetoxysilane which had been activated in water and diluted in Dowanol PM and has a vinyl end group. Ellipsometry measurements of the dried AP8000 adhesion promoter revealed a film thickness of approximately $40 \AA$ A. Since the AP8000 has an extended length of approximately $9 \AA$, this implied that more than a monolayer of the adhesion promoter had been deposited. One specimen set was prepared without adhesion promoter. The wafers were subsequently spin coated with the BCB (Cyclotene 3022, Dow Chemical, Midland, MI) and cured as described below.

The effects of cure temperature and time have been extensively characterized for $\mathrm{BCB}$ resins. ${ }^{26}$ The polymerization of $\mathrm{BCB}$ proceeds through a two-step thermally activated process with an $o$-quinodimethane intermediate. ${ }^{27}$ The polymerization follows first-order reaction kinetics with an activation energy of $150 \mathrm{~kJ} / \mathrm{mol}$. Two BCB cure cycles were used to produce different levels of conversion. A "hard cure" produced at $250{ }^{\circ} \mathrm{C}$ for $1 \mathrm{~h}$ in an inert atmosphere $\left(\mathrm{N}_{2}\right.$ with $\left.<100 \mathrm{ppm} \mathrm{O}_{2}\right)$ was intended to exhibit a fully cross-linked glass structure (approximately 98\% cross link density), and a "soft cure" produced at $210^{\circ} \mathrm{C}$ for $40 \mathrm{~min}$ was intended to exhibit a partially cross-linked sol/gel rubber structure (approximately 80\% cross-link density) which retains some unreacted groups. The mechanical and fracture behavior of BCB has been documented in the standard hard cure condition, and salient mechanical and fracture properties are listed in Table I. The soft-cured BCB is not expected to have significantly different mechanical properties with a modulus and tensile strength of $2.9 \mathrm{GPa}$ and $80 \mathrm{MPa}$, respectively. ${ }^{28}$ 
Three commercially available silica-filled underfill epoxy resins were obtained from manufacturers: FP4527 (Dexter Corp., Industry, CA) and X6-82-5 and X6-82-8 (Zymet Corp., East Hanover, NJ), henceforth referred to as "Dexter," "Zymet-5," and "Zymet-8," respectively. All three consisted of conventional epoxy resins and contained silica filler particles, $10 \mu \mathrm{m}$ or less in diameter, whose primary function is to decrease the thermal expansion coefficient of the cured underfill. The Dexter and Zymet underfills contained 68 and $62 \mathrm{wt} \%$ filler, respectively. The underfills also contained small amounts (approximately $1 \mathrm{wt} \%$ ) of low molecular weight adhesion promoters, of proprietary composition, intended to improve the adhesion of the underfill to various surfaces. The Zymet- 8 underfill was identical to the Zymet-5 formulation except for additional adhesion promoters not present in the -5 formulation. A third Zymet underfill formulation designated "Zymet- 0 " containing no adhesion promoters but otherwise identical to the -5 and -8 formulations was also supplied by the manufacturer for comparison purposes.

The silicon wafers with cured passivation layers were cleaved into 15 by $50 \mathrm{~mm}$ rectangular and $50 \mathrm{~mm}$ square sections. A $15 \mathrm{~mm}$-wide strip of $\mathrm{Au} / \mathrm{Pd}$ was sputtered onto one edge of the square pieces to deliberately degrade adhesion and facilitate interface debonding. The pieces were placed face to face, with two rectangular pieces on each square, and separated by a gap of $75 \mathrm{~mm}$ with tape spacers. Underfill was dispensed into the gap to form the "sandwich" structure depicted in Fig. 1. The underfills were dispensed at $90{ }^{\circ} \mathrm{C}$ and cured in accordance with the manufacturers' recommendations: $165^{\circ} \mathrm{C}$ for $5 \mathrm{~min}$ (Zymet) or $30 \mathrm{~min}$ (Dexter).

Finally, the underfilled specimens were diced with a high-speed wafering blade into strips approximately $5 \mathrm{~mm}$ wide and $50 \mathrm{~mm}$ long. The long side faces of the specimens were polished mechanically to remove surface damage from sawing. Two aluminum loading tabs were epoxy bonded to the end of each specimen to form double cantilever specimens as shown in Fig. 2. Specimens were prepared with selected combinations of adhesion promoters and $\mathrm{BCB}$ cure states using the

TABLE I. Salient mechanical properties for the BCB and underfill materials.

\begin{tabular}{lcccccc}
\hline \hline & $\begin{array}{c}\sigma_{\mathrm{ys}} \\
(\mathrm{MPa})\end{array}$ & $\begin{array}{c}\sigma_{\mathrm{UTS}} \\
(\mathrm{MPa})\end{array}$ & $\begin{array}{c}E \\
(\mathrm{GPa})\end{array}$ & $n$ & $\begin{array}{c}\epsilon_{\mathrm{pl}} \\
(\%)\end{array}$ & $\begin{array}{c}K_{\mathrm{lc}} \\
\left(\mathrm{MPa} \mathrm{m}^{1 / 2}\right)\end{array}$ \\
\hline BCB-soft & $\ldots$ & $80^{\mathrm{a}}$ & $2.9^{\mathrm{a}}$ & $\ldots$ & $\ldots$ & $\ldots$ \\
BCB-hard & 48 & 90 & 2.9 & 0.68 & 5.7 & $0.36^{\mathrm{b}}$ \\
Zymet UF & 36 & 65 & 4 & 0.62 & 1.5 & $\cdots$ \\
Dexter UF & 46 & 51 & 2 & 0.77 & 0.5 & $\ldots$ \\
\hline \hline
\end{tabular}

aDow Cyclotene 4026.

${ }^{\text {bRef. }} 48$.
Zymet-5, -8, and Dexter underfills. For the Zymet-0 underfill, specimens were only prepared using the AP8000/ soft-cured BCB passivation.

\section{B. Underfill mechanical testing}

The tensile strength and modulus of the underfill epoxy resins were measured using miniature tensile dogbone shaped samples with a gauge length of $25 \mathrm{~mm}$ which were tested in general accordance with the American Society for Testing and Materials (ASTM) D-638-98 standard. The underfill formulations were poured into an appropriately shaped mold and fully cured. Tensile tests were performed using an uniaxial mechanical testing system equipped with a $1 \mathrm{kN}$ load cell (Bionix 200, MTS Systems, Minneapolis, MN). Specimens were deformed at a constant displacement rate of $25 \mu \mathrm{m} / \mathrm{s}$. The load versus displacement data were corrected to account for the test system compliance and resulting data plotted in terms of the true stress versus true strain. ${ }^{29}$

\section{Interface adhesion testing}

Double cantilever beam (DCB) specimens to quantitatively measure interface toughness were prepared as described above. The sandwiched geometry precludes gross deformation of the thin polymer layers and prevents the relaxation of any residual film stresses during debonding as has been described elsewhere. ${ }^{5}$ Since the polymer underfill region is relatively stiff and thin com-

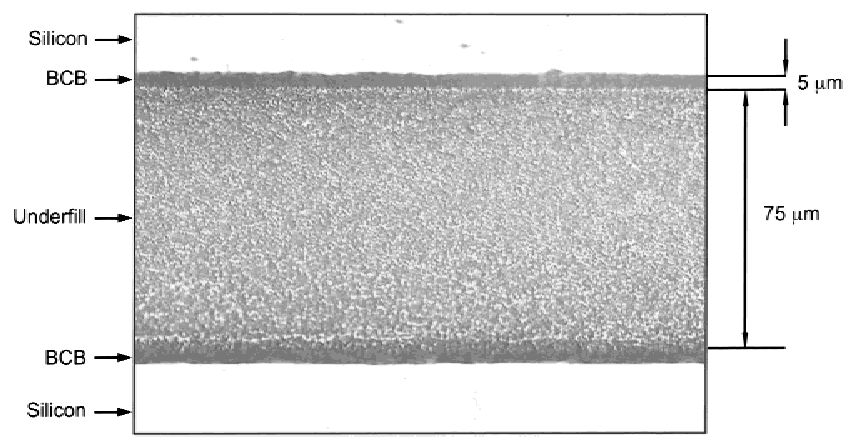

FIG. 1. SEM micrograph of the structure of test specimens showing the underfill and BCB layers sandwiched between two silicon substrates. Not shown is a 250 -nm-thin $\mathrm{LPCVD} \mathrm{SiN}_{X}$ passivation layer between the $\mathrm{BCB}$ and silicon.

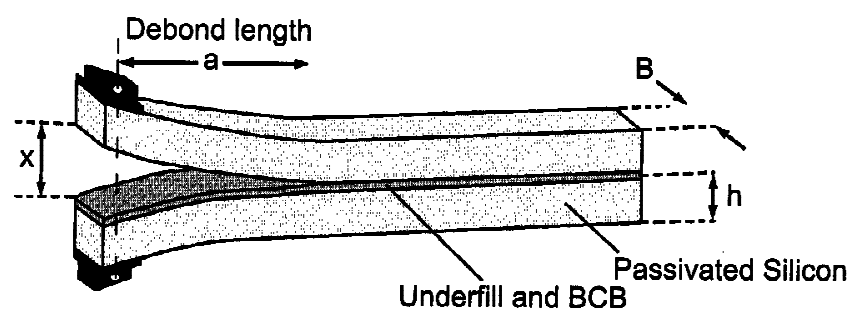

FIG. 2. Schematic illustration of the completed DCB test specimen with relevant dimensions indicated. 
pared to the height of the silicon substrates, the applied strain energy release rate, $G$, can be obtained from standard solutions for homogeneous samples: ${ }^{30}$

$$
G=12 \cdot \frac{P^{2} a^{2}}{B^{2} h^{3} E^{\prime}} \cdot\left(1+0.64 \cdot \frac{h}{a}\right)^{2},
$$

where $P$ is the applied load, $a$ is the length of the interfacial crack, $B$ is the sample thickness, $h$ is the beam height, and $E^{\prime}$ is the plane-strain modulus of the beam (140 GPa for silicon). Note that the effect of a compliant polymer layer between the two beams on the energy release rate can be analyzed using an elastic foundation model. ${ }^{31}$ For the elastic properties and dimensions of our layered specimens this correction is only $1-2 \%$ and is neglected for the sake of simplicity.

The DCB geometry places the interface crack into nearly pure mode-I loading where the interface fracture resistance may be significantly lower than that for mixed mode loading. ${ }^{13,17,32,33}$ Thus, the DCB geometry subjects the interface to the worst case loading mode although note that the lowest fracture resistance is not necessarily obtained under pure mode $\mathrm{I}^{17}$ Further details of interface fracture mechanics including the effect of elastic property mismatch across the interface and phase angle of loading, $\Psi$, has been described in detail elsewhere. ${ }^{7,8}$

Tests were performed using a custom-built highresolution mechanical test system consisting of a load cell and an actuator mounted in a rigid load frame. The load cell and actuator are interfaced to a computer, and the experiments are fully automated. The test system is small enough to be placed inside an environmental chamber to perform tests in a temperature- and humiditycontrolled environment. The length of the interface debond can be measured directly under an optical microscope, or it may be inferred from measurement of the elastic compliance, $\mathrm{d} u / \mathrm{d} P$, of the sample:

$$
a=\left(\frac{d u}{d P}\right)^{\frac{1}{3}} \cdot\left(\frac{B E^{\prime} h^{3}}{8}\right)^{\frac{1}{3}}-0.64 h,
$$

where $u$ is the total displacement of the beam ends. In practice, debond lengths from compliance measurements agreed closely with those measured by optical microscopy. Compliance techniques are more convenient for automated data collection and were used for most of the study.

Measurements of critical adhesion values, $G_{c}$, were performed in ambient laboratory atmosphere. A precrack along the weak $(\mathrm{Au} / \mathrm{Pd})$ interfacial layer was obtained by either loading the specimen monotonically or by applying fatigue loads at $20 \mathrm{~Hz}$. Once the precrack was advanced past the weak layer, critical adhesion values were obtained from the maximum load prior to the onset of rapid debond growth. Tests were conducted under con- stant displacement rates of $15 \mu \mathrm{m} / \mathrm{s}$. Debond growth was indicated by a sudden departure from linearity in the load versus displacement curve. The actuator motion was then quickly reversed to reduce the load on the specimen and arrest crack growth. This procedure was repeated several times to obtain multiple measurements of critical adhesion from a single specimen. At least three nominally identical specimens of each composition and cure condition were tested to ensure reproducibility of the results.

\section{Subcritical debond growth rate testing}

Subcritical debonding tests were facilitated using a load relaxation technique. The general method has been described previously and involves loading the specimen to a predetermined load and then fixing the displacement. ${ }^{10}$ Under these conditions, any debond growth which increases the specimen compliance can be directly related to a corresponding drop in load. With initial load, $P_{0}$, and debond length, $a_{0}$, the debond length at any time during load relaxation is given by

$$
a=-0.64 \cdot h+\left(\frac{\beta}{P}\right)^{\frac{1}{3}},
$$

where

$$
\beta=P_{0} a_{0}^{3} \cdot\left(1+0.64 \cdot \frac{h}{a_{0}}\right)^{3} .
$$

Note that appropriate care must be taken to account for any debond extension that might occur during initial loading.

To study subcritical debond growth under varying environmental conditions, the entire test system was placed within a temperature- and humidity-controlled environmental chamber, allowing several hours for the system to equilibrate. Under computer control, the load drop was continuously monitored over an approximately $36-\mathrm{h}$ period. Using Eqs. (1) and (3), the debond velocity, $\mathrm{d} a / \mathrm{d} t$, was calculated as a function of the crack extension force, $G$, from the load versus time data. Several millimeters of debond extension were observed during the tests. Tests were conducted in laboratory air with 20,50 , and $80 \%$ $\mathrm{RH}( \pm 2 \%)$ and at $0,22,50$, and $70{ }^{\circ} \mathrm{C}\left( \pm 0.5^{\circ} \mathrm{C}\right)$.

\section{E. Interface fractography}

The debond fracture surfaces were examined using optical and scanning electron (SEM) microscopy and $\mathrm{x}$ ray photoelectron spectroscopy (XPS). Optical microscopy during testing allowed in situ observation of the interface debond. XPS scans were made on mating fracture surfaces of failed specimens. The surfaces were characterized using a Surface Science XPS unit with monochromatized $\mathrm{Al} \mathrm{K}_{\alpha}$ x-ray radiation. To precisely identify the debond path and proximity of the silane adhesion promoter, a broad XPS $(0-550 \mathrm{eV})$ scan was made of each mating fracture surface. Detailed scans were then made in regions of the spectra containing peaks of inter- 
est (e.g., O, Si, and N). Depth profiling to analyze compositions beneath the fracture surface was achieved using a high-energy argon gun for sputtering.

\section{RESULTS AND DISCUSSION}

Macroscopic adhesion values measured in terms of critical values of the strain energy release rate, $G_{\mathrm{c}}$, are shown in Fig. 3 and average values together with standard deviations summarized in Table II. An unexpected result was that all of the $\mathrm{BCB}$-passivated wafers failed at the interface between $\mathrm{BCB}$ and silicon nitride, implying that this is the weakest interface in the system. A few specimens displayed limited debonding at the underfill/ $\mathrm{BCB}$ interface, with the debond crossing back and forth from one interface to the other across the BCB layer. This suggests that in these specimens the adhesion of the two interfaces was similar and indeed there was no measurable difference in critical adhesion for debond growth initiating at one interface or the other.

Several features of the adhesion measurements are notable and are discussed in detail in the following sections. The adhesion of the $\mathrm{BCB} /$ nitride interface with the amine-terminated adhesion promoter (AP8000) was higher for soft-cured $\mathrm{BCB}$ than for hard-cured $\mathrm{BCB}$. In addition, for the hard-cured $\mathrm{BCB}$ specimens, adhesion was also enhanced with the amine-terminated adhesion promoter compared to the adhesion promoter with the vinyl end group (AP3000). It is also interesting to note that adhesion of the $\mathrm{BCB} /$ nitride interface is sensitive to the type of underfill. The highest critical adhesion values are associated with the Dexter underfill, and the lowest with Zymet-5. Detailed chemical analysis of the fracture surfaces performed with XPS confirmed that failure was adhesive between the $\mathrm{BCB}$ and nitride; however, the specific failure location with respect to the silane adhesion promoter was found to vary depending on $\mathrm{BCB}$ curing conditions.

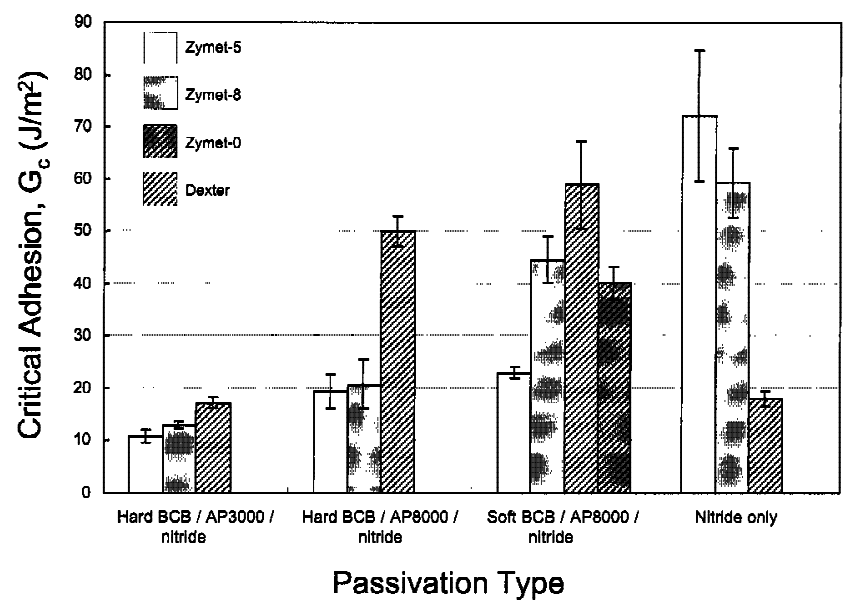

FIG. 3. Critical adhesion values, $G_{\mathrm{c}}$, showing the effects of adhesion promoter, BCB curing conditions, and underfill composition. Average values are the result of at least 9 measurements.
TABLE II. Critical adhesion measurements for underfill/BCBpassivated silicon.

\begin{tabular}{|c|c|c|c|c|}
\hline \multirow{2}{*}{\multicolumn{2}{|c|}{$\begin{array}{c}\text { Values in } \mathrm{J} / \mathrm{m}^{2} \\
\text { Failure at } \\
\text { BCB/nitride } \\
\text { interface }\end{array}$}} & \multicolumn{3}{|c|}{ Si Passivation } \\
\hline & & \multirow{2}{*}{$\begin{array}{c}\begin{array}{c}\text { Hard-cured } \\
\text { BCB/AP3000/ } \\
\text { nitride }\end{array} \\
\ldots\end{array}$} & \multirow{2}{*}{$\begin{array}{c}\begin{array}{c}\text { Hard-cured } \\
\text { BCB/AP8000/ } \\
\text { nitride }\end{array} \\
\ldots\end{array}$} & \multirow{2}{*}{$\begin{array}{c}\begin{array}{c}\text { Soft-cured } \\
\text { BCB/AP8000/ } \\
\text { nitride }\end{array} \\
40 \pm 3.2\end{array}$} \\
\hline Underfill & Zymet-0 & & & \\
\hline & Zymet-5 & $10.8 \pm 1.2$ & $19.4 \pm 3.2$ & $22.9 \pm 1.1$ \\
\hline & Zymet-8 & $12.9 \pm 0.7$ & $20.8 \pm 4.6$ & $44.6 \pm 4.4$ \\
\hline & Dexter & $17.2 \pm 1.1$ & $50.1 \pm 2.9$ & $59.0 \pm 8.4$ \\
\hline
\end{tabular}

\section{A. Effects of adhesion promoter}

Critical adhesion values for the hard-cured BCB specimens (Fig. 3 and Table II) clearly reveal that adhesion was enhanced with the amine-terminated adhesion promoter (AP8000) compared to the vinyl-terminated adhesion promoter (AP3000), irrespective of the underfill composition: $19.4 \mathrm{~J} / \mathrm{m}^{2}$ versus $10.8 \mathrm{~J} / \mathrm{m}^{2}$ for Zymet-5; $20.8 \mathrm{~J} / \mathrm{m}^{2}$ versus $12.9 \mathrm{~J} / \mathrm{m}^{2}$ for Zymet- $8 ; 50.1 \mathrm{~J} / \mathrm{m}^{2}$ versus $17.2 \mathrm{~J} / \mathrm{m}^{2}$ for Dexter. These critical adhesion results are surprising, as it was expected that the amine group in the AP8000 would not react with BCB. Since the specimens with the two different adhesion promoters are in every other way identical, the higher adhesion values obtained with the AP8000 suggest that chemical bonding across the $\mathrm{BCB} /$ nitride interface was improved. The reason for the improvement remains unclear and is the subject of ongoing investigation. More recent studies with specimens containing only BCB layers exhibit enhanced adhesion with the vinyl-terminated AP 3000 compared to the amine-terminated AP $8000 .{ }^{15}$ This suggests that the AP 3000 might be degraded in the presence of the underfill chemistry, an effect discussed in more detail in subsequent sections.

\section{B. Effects of BCB cure}

The critical adhesion values for hard- and soft-cured $\mathrm{BCB}$ with the same adhesion promoter (AP8000) reported in Fig. 3 and Table II show that the soft-cured BCB specimens produce consistently higher fracture energies irrespective of underfill composition. The $G_{\mathrm{c}}$ values for hard- and soft-cured specimens, respectively, are $19.4 \mathrm{~J} / \mathrm{m}^{2}$ versus $22.9 \mathrm{~J} / \mathrm{m}^{2}$ for specimens underfilled with Zymet-5, $20.8 \mathrm{~J} / \mathrm{m}^{2}$ versus $44.6 \mathrm{~J} / \mathrm{m}^{2}$ for Zymet-8, and $50.1 \mathrm{~J} / \mathrm{m}^{2}$ versus $59.0 \mathrm{~J} / \mathrm{m}^{2}$ for Dexter underfill. There are two potential explanations for the difference in adhesion between hard- and soft-cured BCB specimens. One is that the hard- and soft-cured BCB may exhibit different deformation behavior, altering the amount of energy dissipated through plastic deformation in the $\mathrm{BCB}$ and thereby the critical adhesion. However, significant differences in the mechanical properties of the two cure states are not expected. ${ }^{28}$ Another possibility is that the chemical structure of the adhesion promoter at the 
$\mathrm{BCB} /$ nitride interface is altered by the $\mathrm{BCB}$ cure. Detailed XPS studies of the interface region together with subcritical debond-growth activation energy data support this scenario and are discussed below and in the following sections.

Nitrogen in the amine-end group of the AP8000 adhesion promoter provides an ideal elemental peak in XPS spectra to facilitate studies of the interface debond location. The positions of XPS elemental peaks are shifted by localized chemical bonding, allowing us to distinguish nitrogen in the AP8000's amine groups from nitrogen in the silicon nitride. The vinyl functional group in the AP3000, composed of carbon and oxygen, is more difficult to detect, as large amounts of these elements are present in the specimens, both in the underfill and as a result of contamination after exposure to the environment. Thus, the XPS studies presented are restricted to specimens containing the amine-end group adhesion promoter.

A schematic illustration of the $\mathrm{BCB} /$ nitride interface containing the AP8000 adhesion promoter is shown in Fig. 4. As previously mentioned, the silane adhesion layer was initially approximately $40-\AA$ thick with multiple layers of molecules. Bonding between the adhesion promoting molecules is not explicitly shown due to the complexity of potential bond sites. After BCB deposition and prior to cure, all of the AP8000 specimens were assumed to have this structure. XPS survey scans and specific scans of the nitrogen $(1 s)$ peak were obtained from mating debond fracture surfaces and are shown in Fig. 5 for soft- and hard-cured BCB specimens. For the soft-cured specimens, spectra taken from the BCB side of the fracture showed no evidence of nitrogen on the surface [Fig. 5(a)]. On the $\mathrm{SiN}_{X}$ side of the fracture a strong nitrogen signature resulting from a double peak was apparent as shown in Fig. 5(b). This is consistent with the presence of nitrogen in two binding states: one peak at $397 \mathrm{eV}$ associated with nitrogen in $\mathrm{SiN}_{X}$ and a second at $399 \mathrm{eV}$ associated with nitrogen in an organic matrix (the

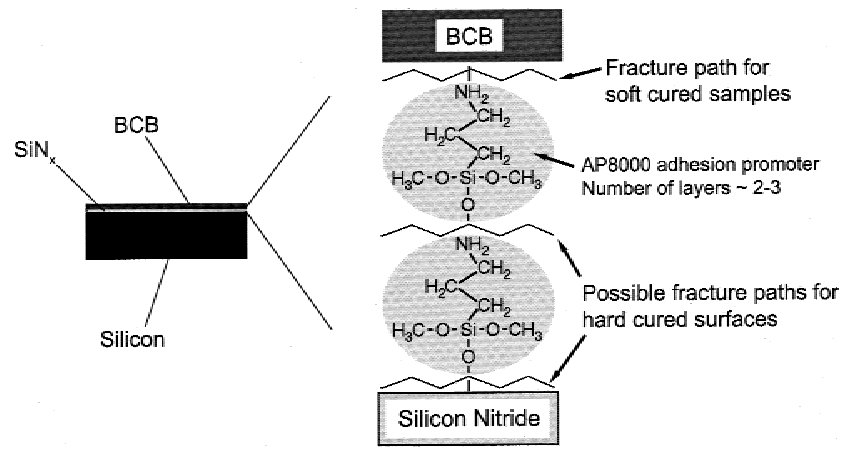

FIG. 4. Schematic illustration of the $\mathrm{BCB} / \mathrm{SiN}_{X}$ interface region showing the presence of the amine-terminated adhesion promoter (AP8000) attached to the nitride passivation. The adhesion promoter layer thickness was approximately $40 \AA$ implying the presence of more than a monolayer. Debond paths determined from XPS studies are indicated.

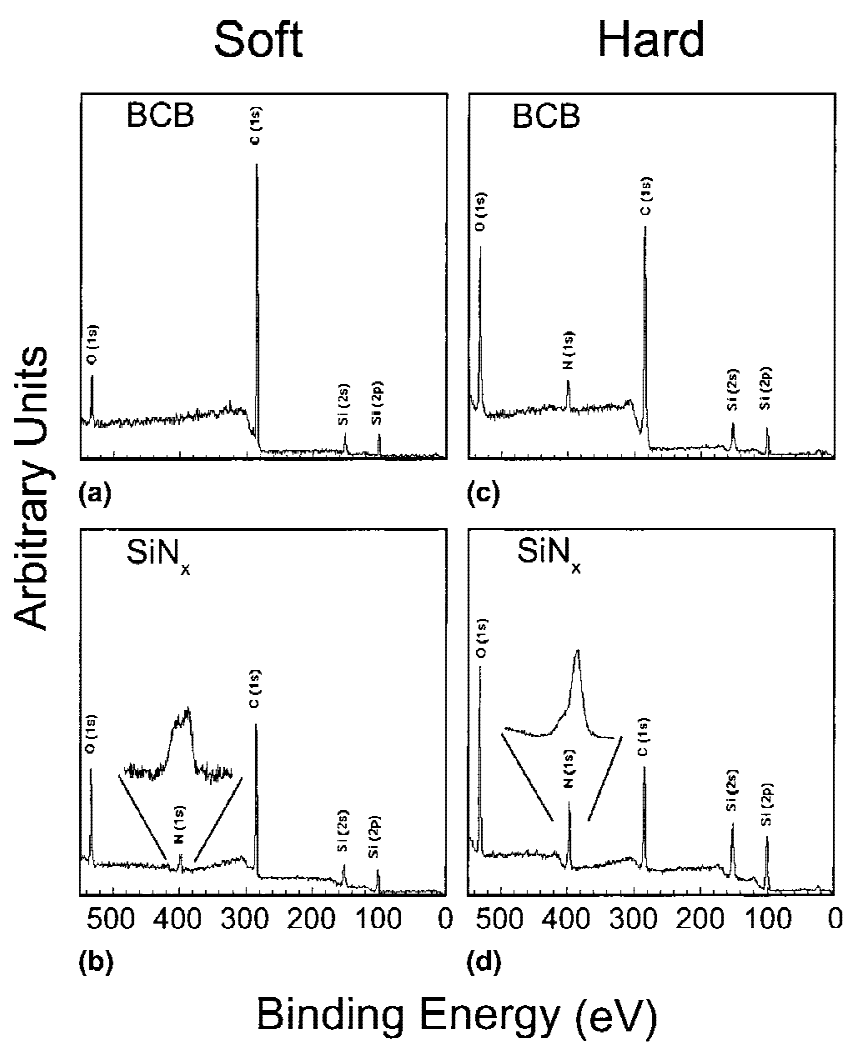

FIG. 5. XPS spectra obtained from fracture surfaces of specimens with the amine-terminated adhesion promoter (AP8000) showing for the soft-cured BCB the (a) BCB side and (b) the $\mathrm{SiN}_{X}$ side and specimens with hard-cured $\mathrm{BCB}$ (c) the $\mathrm{BCB}$ side and (d) the $\mathrm{SiN}_{X}$ side. Inserts show the results of detailed scans of interesting peaks.

adhesion promoter). ${ }^{34}$ From these spectra we concluded that, in the soft-cured specimens, the adhesion promoter layer remained bonded to the surface of the $\operatorname{SiN}_{X}$. Debonding occurred between the adhesion promoter and $\mathrm{BCB}$ layers or slightly in the $\mathrm{BCB}$ as depicted in the figure. More precision regarding the debond path location is compromised by the electron escape depth for the polymer layers of approximately 5-50 .

XPS spectra from hard-cured specimens, shown in Figs. 5(c) and 5(d), are clearly different. The BCB side of the fracture surface displayed a nitrogen peak whose binding energy was consistent with the amine group. In addition, the $\mathrm{SiN}_{X}$ side of the fracture surface no longer exhibits the characteristic strong double peak that was seen in the soft-cured specimen. There is a faint peak from the adhesion promoter, but most of the nitrogen signal is from $\operatorname{SiN}_{X}$. Debonding in this specimen therefore appears to have occurred somewhere within the adhesion promoter layer (Fig. 4). Further evidence that the chemical structure of the adhesion promoter was degraded significantly by the hard cure process is discussed next.

XPS compositional depth profiles provided additional information on the effect of BCB curing on the interface composition. Two surfaces were studied: the $\mathrm{SiN}_{X}$ side of 
the fracture surface from a soft-cured specimen, which displayed the double nitrogen peak, and the $\mathrm{BCB}$ side of a fracture surface from a hard-cured specimen, which displayed the nitrogen signature of the adhesion promoter. The sputter etch rates for polymers in the XPS system typically range from 120 to $170 \AA / \mathrm{min}$. The results of the depth profiling for a soft-cured specimen are plotted in Fig. 6(a). After only $6 \mathrm{~s}$ of sputtering the higher energy peak associated with nitrogen in the amine group of the adhesion promoter disappears and it is concluded that the amine group must have been within the first few monolayers of the fracture surface. This is consistent with the simple model discussed previously

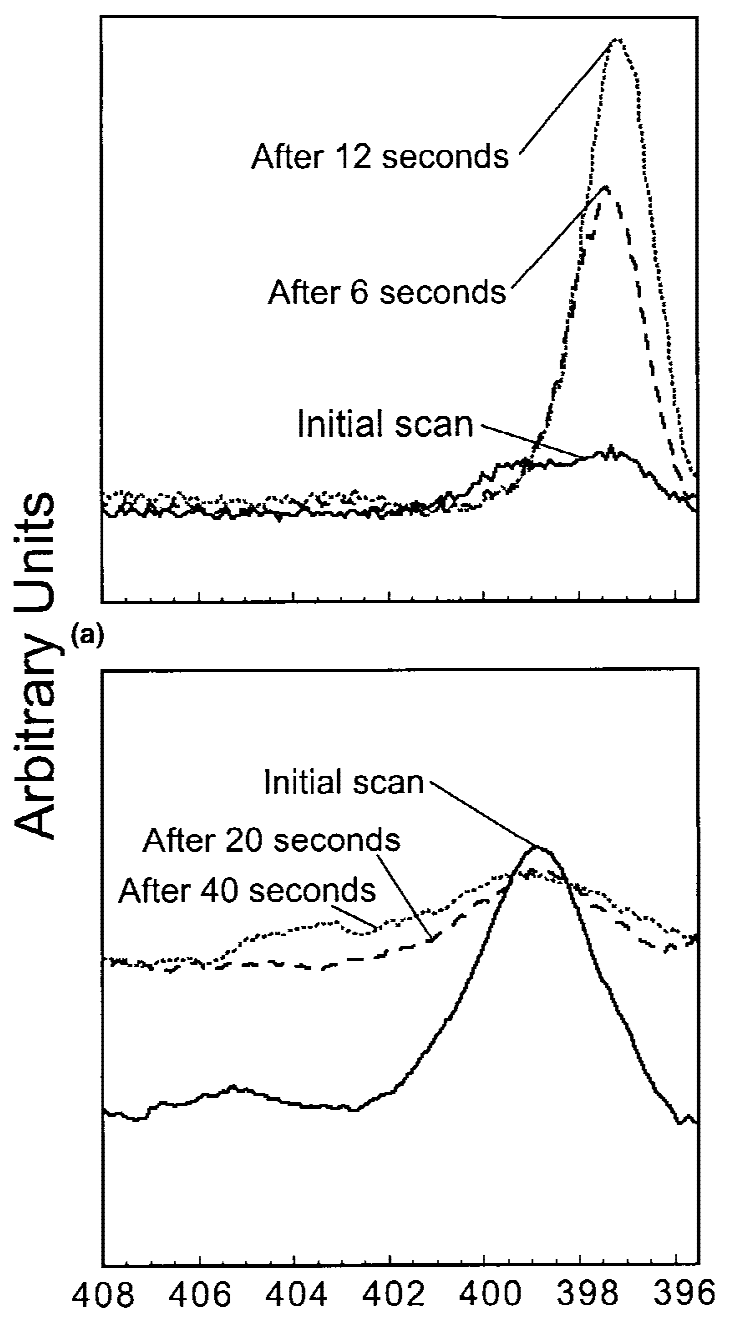

(b)

\section{Binding Energy (eV)}

FIG. 6. XPS scans taken at different locations after depth profiling into (a) the $\mathrm{SiN}_{X}$ side of the fracture surface for a soft-cured BCB specimen and (b) the BCB side of a hard-cured specimen. Scans are centered on the nitrogen peak associated with the nitride $(397 \mathrm{eV})$ and amine group $(399 \mathrm{eV})$ for the soft- and hard-cured specimens, respectively.
(Fig. 4). Note that there is a corresponding increase in the nitrogen peak associated with $\mathrm{SiN}_{X}$ with each scan as the adhesion promoter is removed.

Hard-cured BCB produced different compositional profiles as evidenced by three spectra taken from the BCB side of the fracture surface shown in Fig. 6(b). The strong nitrogen peak with a binding energy of $399 \mathrm{eV}$ indicative of the amine group is clearly present on the fracture surface and persists in subsequent spectra taken after sputter etching into the BCB layer. Even after $40 \mathrm{~s}$ of sputtering, corresponding to a minimum sputter depth of $80 \AA$, a weak nitrogen signal was still present. With hard curing, the adhesion promoter therefore appears to have diffused away from the interface and into the $\mathrm{BCB}$ layer leaving less than a monolayer on the $\operatorname{SiN}_{X}$ surface [Fig. 5(d)]. It is not clear whether the increased time and temperature of the hard cure assists in the decomposition of the adhesion promoter which would allow the amine group to diffuse more rapidly. However, clearly the overall effect was to degrade chemical bonding at the interface and significantly lower the macroscopic adhesion values (Fig. 3).

\section{Effect of underfill composition}

A particularly interesting feature of the critical adhesion data shown in Fig. 3 is that the adhesion energy of the $\mathrm{BCB} /$ nitride interface was sensitive to the underfill composition. For example, adhesion values for the hardcured BCB/AP3000/nitride interface are $10.8 \mathrm{~J} / \mathrm{m}^{2}$ when the structure is underfilled with Zymet $-5,12.9 \mathrm{~J} / \mathrm{m}^{2}$ for Zymet- 8 , and $17.2 \mathrm{~J} / \mathrm{m}^{2}$ for the Dexter underfill. All of the specimens displayed this trend, with critical adhesion values lowest for the Zymet-5 underfill, intermediate for the Zymet-8, and highest for the Dexter underfill.

Several mechanisms have the potential to explain the variation of the measured adhesion values with underfill type. Plastic deformation surrounding the debond tip in the 5- $\mu \mathrm{m}$-thick BCB layer or even in the underfill layer itself may be affected by the mechanical properties of the two different epoxy underfill compositions. A similar effect could result from settling of the silica filler particles prior to underfill cure. Such settling can alter the concentration of silica filler particles near the interface, significantly changing the mechanical properties of the underfill in the region near the debond tip. Finally, low molecular weight species, most likely associated with the adhesion promoting packages employed in the underfill materials, may diffuse through the BCB and degrade the adhesion promoter. We explore these possibilities in more detail the following sections.

Note that it is possible that chemical bonding at the $\mathrm{BCB} / \mathrm{SiN}_{X}$ interface may be affected by differences in thermal processing for the different underfills. However, the only differences in processing conditions during specimen fabrication were the cure times of the two underfills, 30 min for the Dexter and 5 min for the Zymet 
underfills. To determine whether the additional cure time affects critical adhesion values, specimens with the Zymet- 8 underfill were prepared and subjected to an additional $25 \mathrm{~min}$ anneal at $165^{\circ} \mathrm{C}$. No significant difference in adhesion was observed for the annealed specimens.

\section{Underfill mechanical properties}

The true stress versus strain behavior of the underfill materials were assessed using tension tests on bulk underfill specimens and representative curves are shown in Fig. 7 and summarized in Table I. The specimens exhibited linear elastic behavior to applied strains of approximately $0.8 \%$ and approximately $1.8 \%$ for the Zymet and Dexter compositions, respectively. The Young's modulus of the Zymet underfill (4 GPa) was significantly higher than that of the Dexter underfill $(2 \mathrm{GPa})$. The $0.2 \%$ offset yield stress, $\sigma_{\mathrm{ys}}$, of the Zymet underfill (36 MPa) was lower than the Dexter yield stress (46 MPa). All specimens exhibited similar work hardening behavior and failed by brittle fracture at strains of approximately $3-4 \%$. No discernible differences were apparent for the Zymet-5 and Zymet-8 compositions. This was anticipated since the only difference between the two compositions was the presence of an additional adhesion promoter in the Zymet- 8 which was not expected to impact bulk mechanical properties.

Plastic energy dissipation in ductile layers has been shown to have a large effect on the interface debond energy of thin-film structures. ${ }^{5,12,24}$ Models of the

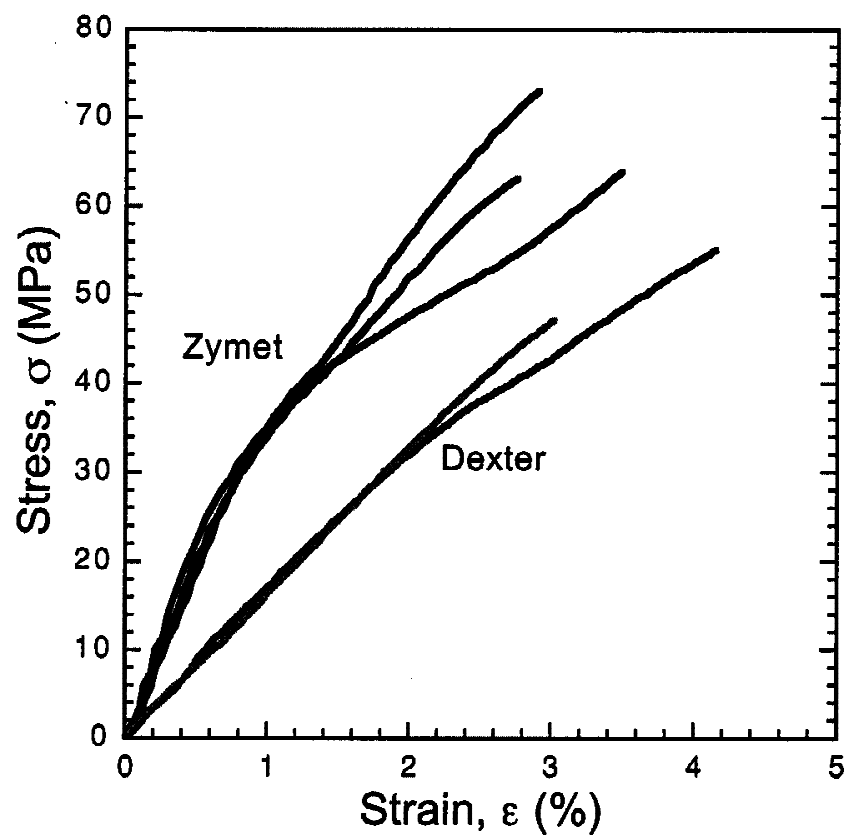

FIG. 7. Representative true stress versus strain plots from tension tests of the Zymet and Dexter underfill materials. The Dexter material exhibited slightly higher yield and hardening behavior but with a reduced elastic modulus. debonding process that include the cohesive strength of the interface and the thickness and elastic and plastic deformation properties of adjacent ductile layers have been shown to adequately predict the increase in interface fracture energy with increasing plastic deformation for a number of layered systems. ${ }^{12,35,36}$ However, the yield and plastic work hardening behavior of the two underfill compositions are similar and are not expected to significantly affect $G_{\mathrm{c}}$. In fact, the Zymet underfill has a somewhat lower yield strength and exhibits larger plastic strains to failure and might therefore be expected to result in larger values of $G_{\mathrm{c}}$.

Interface fracture energy simulations were therefore conducted using the embedded process zone (EPZ) model $^{35,37}$ to explore the role of the elastic modulus of the epoxy underfill layers on plastic deformation in the BCB layer during debonding. The EPZ model includes the rupture process at the debond tip and a surrounding zone which experiences large plastic strains in the adjacent BCB layer. A traction-separation law characterizes the interface rupture process and is governed by a maximum separation stress, $\hat{\sigma}$, and intrinsic interface fracture resistance $G_{0}$. The ductile layer was characterized with an elastic/power-law hardening relationship with strain hardening exponent $\mathrm{n}$. For these simulations the epoxy underfill layer was assumed to be elastic with modulus $E_{\mathrm{UF}}=2$ and $4 \mathrm{GPa}$ for the Dexter and Zymet, respectively. The BCB was modeled with average mechanical properties given in Table I. $G_{0}$ and $\hat{\sigma}$ are not known precisely, and a value of $G_{0}=5 \mathrm{~J} / \mathrm{m}^{2}$ was assumed with $\hat{\sigma}$ taken as a fitting parameter.

The most important variables effecting the value of $G_{\mathrm{c}}$ are considered to be $G_{0}$, the ratio $\hat{\sigma} / \sigma_{\mathrm{ys}}, n$, and the phase angle of loading, $\Psi \cdot{ }^{38}$ However, the present simulations revealed that the elastic modulus of the epoxy underfill layer has a surprisingly large effect on steady-state fracture energy, $G_{\mathrm{c}}$, as shown in Fig. 8 for a range of values of $\hat{\sigma} / \sigma_{\mathrm{ys}}$. While the precise value of $\hat{\sigma}$ is not known, particularly where complex interface chemistries are concerned, reasonable values are likely to be in the range of $E_{\mathrm{BCB}} / 10$ to $E_{\mathrm{BCB}} / 60$, giving $\hat{\sigma} / \sigma_{\mathrm{ys}}=1$ to 6 . Over this range of interface strengths, it is clearly apparent from the simulations that the more compliant Dexter underfill results in significantly more plasticity in the $\mathrm{BCB}$ and hence raises the value of $G_{\mathrm{c}}$, particularly for stronger interfaces. Therefore, the effect of the modulus difference of the two underfill layers may clearly be sufficient to account for the difference in measured values of $G_{\mathrm{c}}$.

Note that we have assumed that the values of $\hat{\sigma}$ and $G_{0}$ are unchanged for specimens prepared with different underfill compositions. It is possible that diffusion through the $\mathrm{BCB}$ of a low molecular weight species associated with the adhesion promoters in the underfill materials degraded the strength of the $\mathrm{BCB} / \mathrm{SiN}_{X}$ interface by bonding with the adhesion promoter at that interface. 


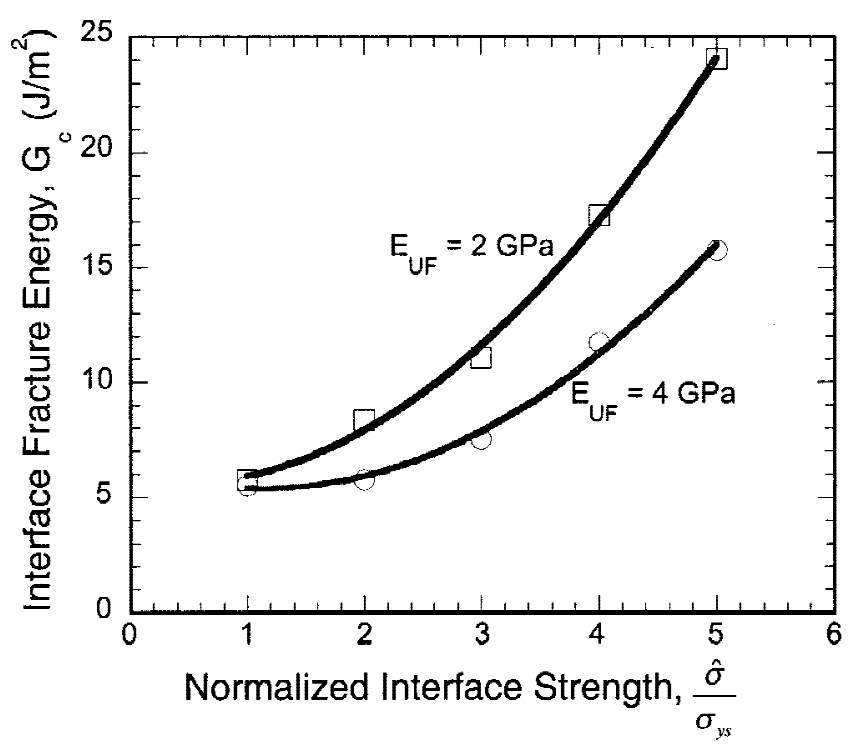

FIG. 8. Dependence of interface fracture energy, $G_{c}$, on the normalized interface strength, $\hat{\sigma} / \sigma_{\text {ys }}$, obtained from interface fracture simulations for debonding of the $\mathrm{BCB} /$ nitride interface where the $\mathrm{BCB}$ is treated as an elastic/power-law hardening layer, and the epoxy underfill layer is assumed to be elastic $\left(E_{\mathrm{UF}}=2\right.$ and $\left.4 \mathrm{GPa}\right)$. The significant effect of decreasing the underfill elastic modulus on plasticity contributions to $G_{\mathrm{c}}$ is clearly apparent.

However, adhesion values measured for the Zymet- 0 specimens which did not contain an adhesion promoting package showed similar values to the Zymet- 8 specimens and therefore do not support this hypothesis.

\section{E. Underfill settling}

Settling of silica beads toward one interface during underfilling and subsequent curing may result in significant variation of mechanical properties through the underfill. The lower region containing a greater concentration of silica beads may be expected to be stiffer and stronger, while the denuded region will be more compliant and weaker. ${ }^{39,40}$ Settling was observed in the specimens and representative SEM micrographs taken from polished cross-sections of the underfill regions are shown in Fig. 9. Settling was more pronounced in the Dexter underfill than in the Zymet underfill, although some settling was apparent in all specimens examined.

In a separate study, the effect of such settling on local plastic deformation during debonding has been investigated. ${ }^{41}$ Higher adhesion values were measured for debonding of the interface adjacent to the silica-denuded region compared to that adjacent to the silica-enriched region. This behavior was rationalized in terms of the increased plastic deformation that occurs in the denuded region of the underfill. However, in the present study, debonding was restricted to the interface adjacent to the silica-enriched side of the underfill layer where the initial weak region was located. Therefore, the data cannot be

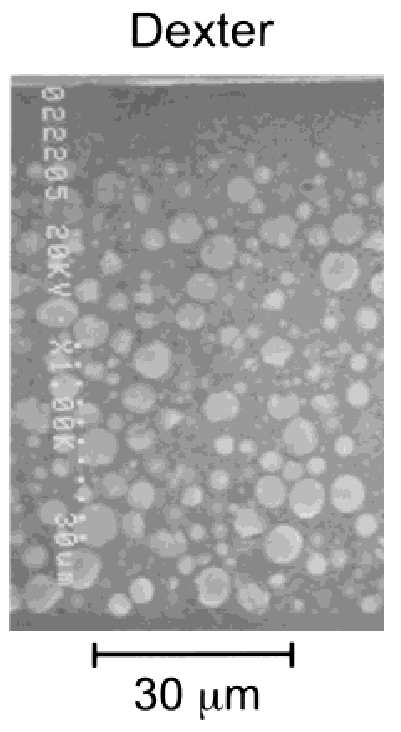

(a)

\section{Zymet}

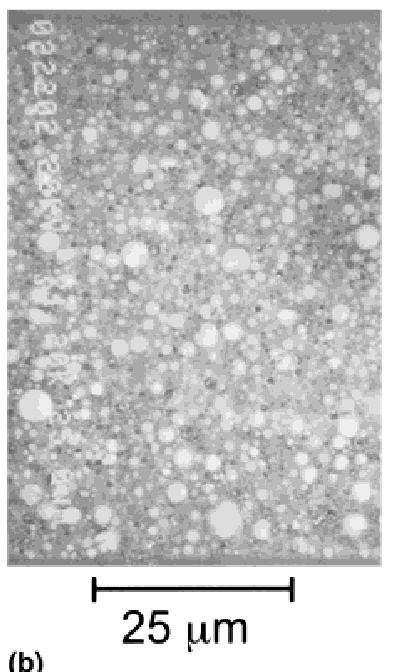

(b)

FIG. 9. SEM micrographs taken from polished sections of the underfill underfill region of (a) the Dexter and (b) the Zymet underfill materials. Evidence of settling of the silica beads to the lower interface were apparent for both compositions.

explained by inadvertently debonding opposite sides of the underfill layer in different specimen sets. In addition, the silica beads in the Dexter underfill were observed to settle more toward the interface of interest compared to the Zymet which we would expect to produce lower rather than higher adhesion values. Clearly, the settling effect does not explain the present results, although settling does have an effect on adhesion of interfaces and is the subject of ongoing research. ${ }^{41}$

\section{F. Subcritical debonding}

Detailed studies of subcritical debonding of $\mathrm{BCB} /$ nitride interfaces were limited to specimens with the amine terminated adhesion promoter and Zymet-8 under- 
fill, although all the specimens displayed such behavior. The subcritical debond-growth rate, $\mathrm{d} a / \mathrm{d} t$, as a function of the applied strain energy release rate, $G$, from tests performed at $22{ }^{\circ} \mathrm{C}$ and $50 \% \mathrm{RH}$ is shown in Fig. 10 for hard- and soft-cured BCB specimens. The critical adhesion values, $G_{\mathrm{c}}$, are included in the plot for comparison. Time-dependent debonding was measured over 4 orders of magnitude from $10^{-4} \mathrm{~m} / \mathrm{s}$ to values approaching $10^{-9} \mathrm{~m} / \mathrm{s}$. Such subcritical debonding behavior is associated with a stress-corrosion crack-growth processes and involves the synergistic effects of an environmental species, in this case moisture, and strained crack-tip atomic bonds. The phenomena does not occur in all material and environmental couples, and the reaction kinetics often depend sensitively on the activity of the environmental species and the temperature. In the present specimens, it is notable that the threshold for subcritical debonding, $G_{\mathrm{TH}}$, is typically only approximately $55 \%$ of $G_{\mathrm{c}}$ for both the soft- and hard-cured specimens. Note that the presence of a true subcritical debond-growth threshold was not observed in the present study and an operational definition for $G_{\mathrm{TH}}$ was employed at debond growth rates of approximately $10^{-9} \mathrm{~m} / \mathrm{s}$. Clearly, the presence of such subcritical debonding at applied loads significantly below $G_{\mathrm{c}}$ has important implications for the longterm reliability of interfaces prone to time dependent debonding.

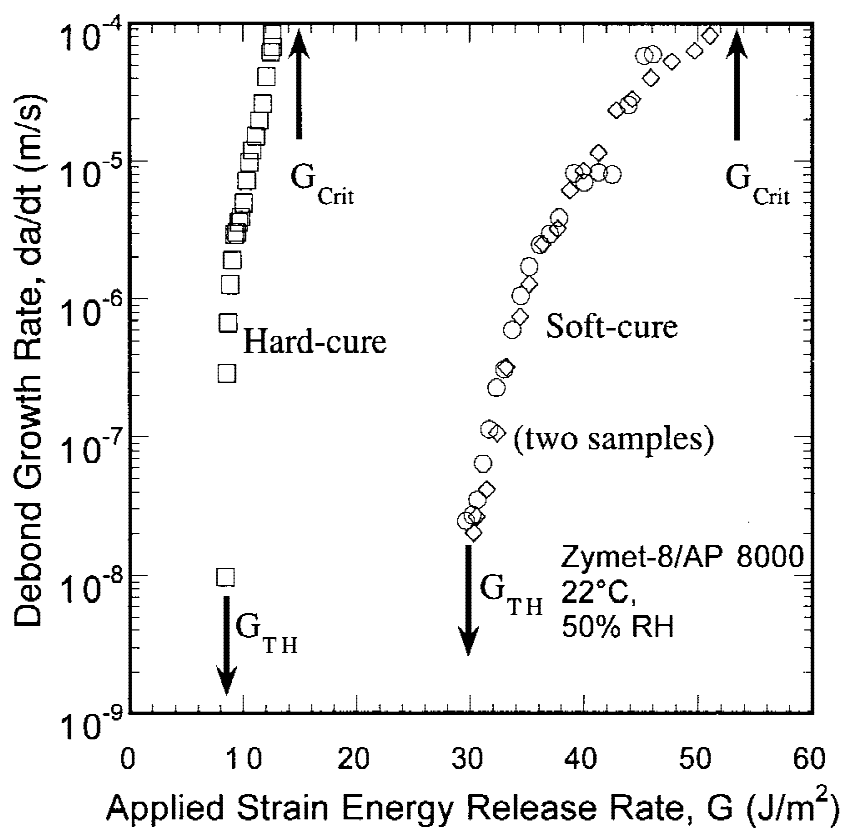

FIG. 10. Subcritical debond-growth rate behavior showing the debond-growth rate, $\mathrm{d} a / \mathrm{d} t$, as a function of the debond strain energy release rate, $G$, for soft- and hard-cured BCB layers measured at $22{ }^{\circ} \mathrm{C}$ and $50 \%$ RH. Subcritical debond-growth rate thresholds, $G_{\mathrm{TH}}$, are only approximately $55 \%$ of $G_{\mathrm{c}}$.
The effects of temperature and humidity on the subcritical debond-growth rate behavior were examined at temperatures of 0,22 , and $50{ }^{\circ} \mathrm{C}$ with $50 \% \mathrm{RH}$ and at $\mathrm{RH}$ values of $20 \%, 50 \%$, and $85 \%$ with temperature fixed at $50{ }^{\circ} \mathrm{C}$. Debond growth-rate curves showing the effect of temperature on both soft- and hard-cured specimens are presented in Fig. 11. Increasing temperature has a significant effect on debond-growth rates. For the temperature rates explored, a $20^{\circ} \mathrm{C}$ increase in temperature results in approximately 2 orders of magnitude increase in growth rates for a given value of $G$. $G_{\mathrm{TH}}$ values are also significantly decreased with increasing temperature.

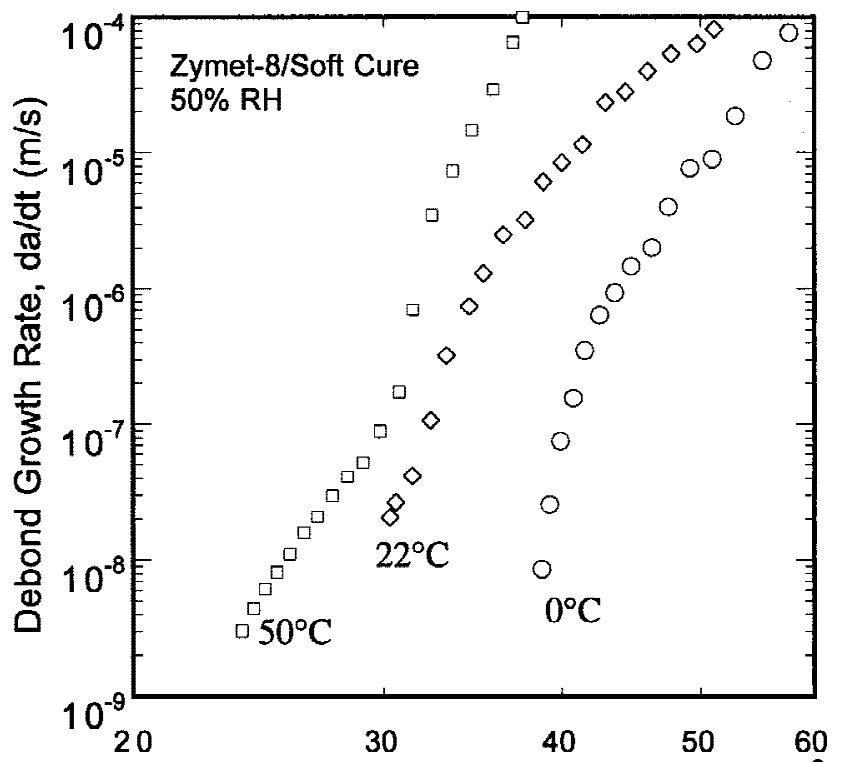

(a) Applied Strain Energy Release Rate, G (J/m $\left.\mathrm{m}^{2}\right)$

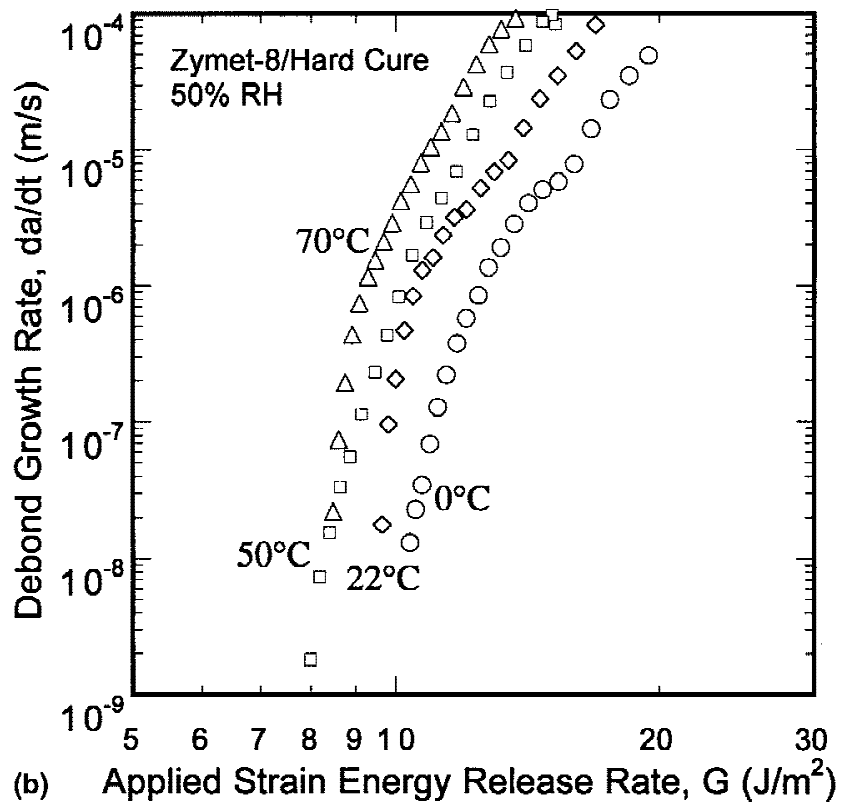

FIG. 11. Subcritical debond-growth rate curves indicating the effect of temperature on debonding of (a) soft-cured BCB specimens and (b) hard-cured specimens. 
Following the pioneering work of Wiederhorn et al., ${ }^{42}$ the stress-corrosion process may be modeled as a thermally activated chemical reaction in which the stress-free activation energy $E^{*}$ is determined by fitting the measured growth rate data to a relationship of the form

$$
\frac{d a}{d t}=v_{0} \exp \left(\frac{-E^{*}+b G}{R T}\right)
$$

where $R$ is the gas constant, $T$ the absolute temperature, and $v_{0}$ (which is proportional to the activity of the environmental species) and $b$ are constants depending on the material and environmental combination. A linear fit was performed on the higher growth rate region of the subcritical debond-growth rate curves, and a representative growth rate was obtained from the fitted curve at a given value of $G$. Arrhenius plots to determine the activation energy are shown in Fig. 12.

It is immediately apparent from the figure that the growth rates are thermally activated and the activation energies determined from the slopes of the Arrhenius plots were $84.1 \mathrm{~kJ} / \mathrm{mol}$ for the soft-cured $\mathrm{BCB}$ and $42.7 \mathrm{~kJ} / \mathrm{mol}$ for the hard-cured BCB. These values correspond to 0.87 and $0.44 \mathrm{eV} / \mathrm{bond}$ for the soft- and hardcured $\mathrm{BCB} /$ nitride interfaces, respectively. While there is a paucity of activation energy data for stress-corrosion cracking in bulk polymers and almost no data for subcritical debonding at interfaces with polymers, the activation energy for the soft cured specimens are almost identical to the activation energy of $85 \mathrm{~kJ} / \mathrm{mol}$ reported for $\mathrm{C}-\mathrm{C}$ bond rupture. ${ }^{43,44}$ The activation energy values are also similar to those reported for subcritical cracking of bulk polyethylene in moist environments ${ }^{45}$ and subcritical debonding of interfaces between a polymer epoxy resin and metal substrate. ${ }^{2,16}$ The difference in activation energies between the soft- and hard-cured specimens is

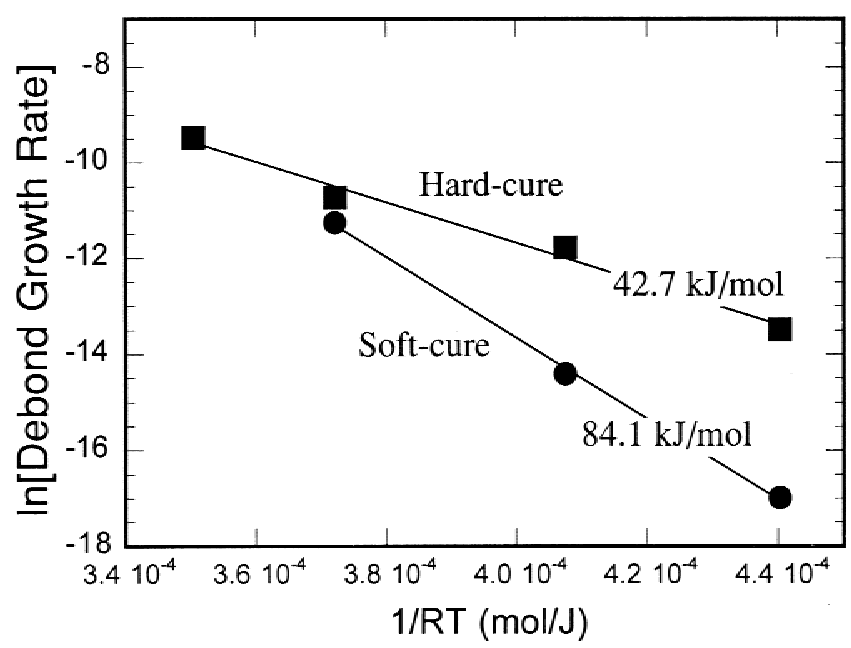

FIG. 12. Arrhenius plots used to determine the activation energy for subcritical debonding of both soft- and hard-cured BCB specimens. suggestive of a significant difference in chemical bonding at the interface, consistent with the XPS studies described above.

The effects of humidity on the debond-growth rate at $50{ }^{\circ} \mathrm{C}$ are shown in Fig. 13 for both soft- and hard-cured BCB specimens. For the soft-cured specimens, humidity has little effect on the mid-growth rate regime (approximately $10^{-3}-10^{-6} \mathrm{~m} / \mathrm{s}$ ); however, increasing humidity has some effect on near-threshold growth rates and appears to noticeably lower the threshold $G_{\mathrm{TH}}$ [Fig. 13(a)]. Increasing humidity has little apparent effect for the hard-cured BCB specimens over the entire mid-growth rate regime (approximately $10^{-3}-10^{-6} \mathrm{~m} / \mathrm{s}$ ), and only
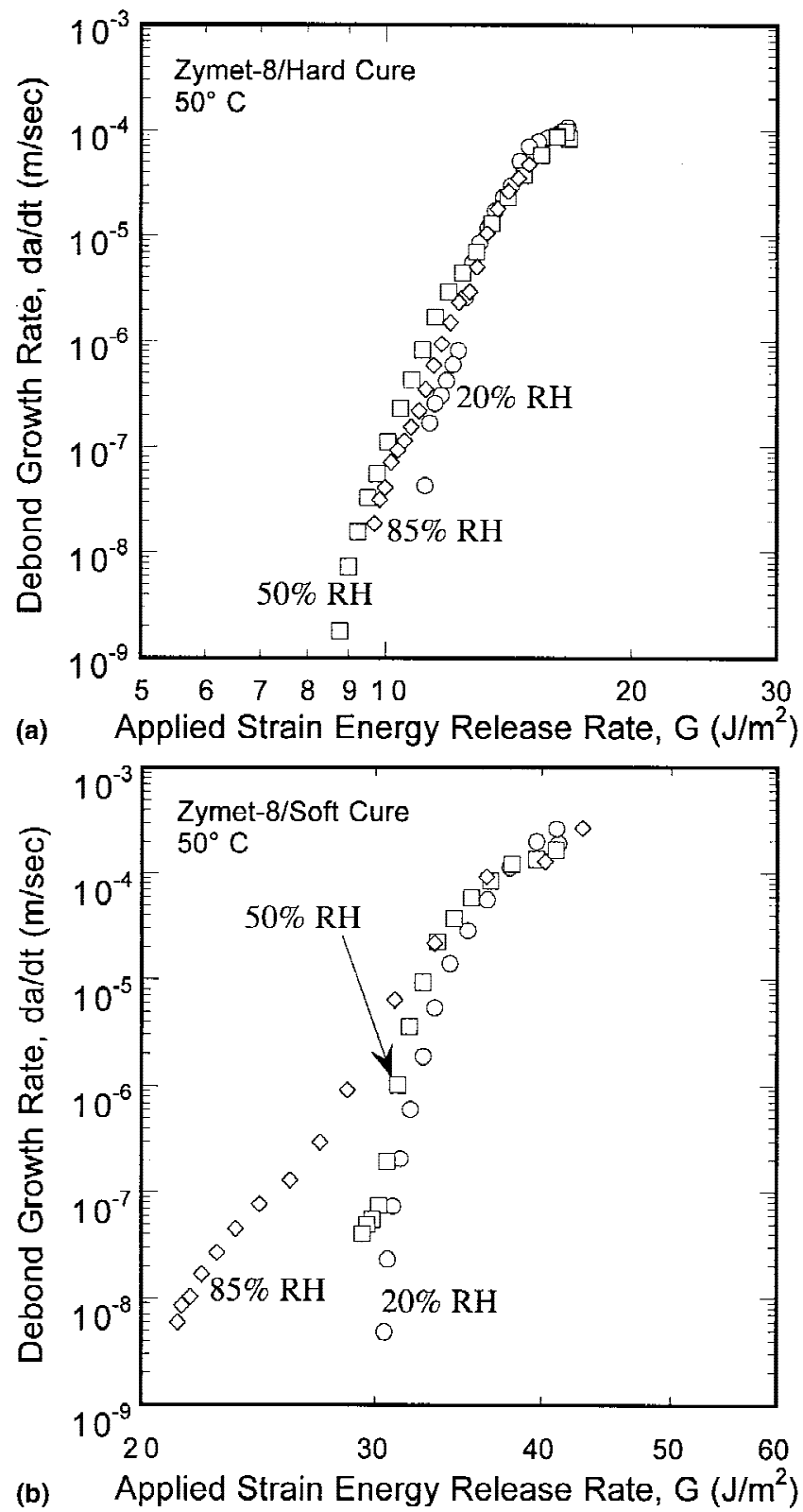

FIG. 13. Subcritical debond-growth rate curves indicating the effect of moisture content on debonding of (a) hard-cured BCB specimens and (b) soft-cured specimens. 
marginally increases near-threshold growth rates [Fig. 13(b)]. The difference in moisture sensitivity between the hard- and soft-cured specimens is again consistent with the hypothesis that the curing process changes the chemical characteristics of the $\mathrm{BCB} /$ nitride interface.

Subcritical cracking associated with environmental species often follows first-order reaction kinetics. Reaction kinetic models predict that the crack velocity is proportional to the concentration of water, $\left[\mathrm{H}_{2} \mathrm{O}\right]$, in the environment according to $\mathrm{d} a / \mathrm{d} t=v_{0}\left[\mathrm{H}_{2} \mathrm{O}\right] k_{\mathrm{r}}$, where $v_{0}$ is a constant and $k_{\mathrm{r}}$ the reaction rate. ${ }^{42}$ The $\mathrm{H}_{2} \mathrm{O}$ concentration is related to the chemical activity of the water which in a gas is proportional to the partial pressure of the water vapor or relative humidity. Therefore increasing humidity should shift of the entire debond-growth rate curve to lower $G$ values or for fixed values of $G$ to higher growth rates. Noting that in the present experiments the relative humidity was changed from 20 to $85 \%$ at constant temperature, we estimate $\left[\mathrm{H}_{2} \mathrm{O}\right]_{85 \%} /\left[\mathrm{H}_{2} \mathrm{O}\right]_{20 \%}$ $=v_{85 \%} / v_{20 \%} \sim 4$, which for a given applied $G$ implies that growth rates should be increased by a factor of 4 . Within the scatter of the present debond-growth rate data such increases are not apparent at growth rates above approximately $10^{-5} \mathrm{~m} / \mathrm{s}$, but lower growth rates are increased by values consistent with the predicted amount.

Note that the above comparisons must be conducted at constant temperature since temperature effects the kinetics of the process through both the usual activation energy term [Eq. (5)] as well as the activity of the environmental species. The activity is related to the chemical potential, $\mu$, of the water molecules, which is a function of the partial pressure $P_{\mathrm{H}_{2} \mathrm{O}}$ :

$$
\mu=\mu^{0}+R T \ln P_{\mathrm{H}_{2} \mathrm{O}},
$$

where $\mu^{0}$ is the chemical potential of water at standard temperature and pressure. The temperature dependence of $\mu$ is apparent. For the present BCB interface, the effect of temperature appears to be dominant in the mid-growth rate regime. This is demonstrated in Fig. 14, where the change in $G$ as a function of $\mathrm{H}_{2} \mathrm{O}$ partial pressure is plotted for a fixed debond velocity. It is clear that when only the activity of water is increased, the corresponding $G$ values are not significantly shifted. However, if both temperature and activity are varied, the values of $G$ shift by a large amount. This is in stark contrast to interfaces between metal or nitride layers with inorganic silica glasses where the activity of moisture in the environment has a significant effect on debond kinetics. ${ }^{46}$ For these interfaces, varying both temperature and activity results in changes in the debond growth rates that are similar to shifts produced by varying only the activity.

The predicted sensitivity to moisture content anticipated by the chemical reaction rate models is, however, not unambiguously established by the present data. It

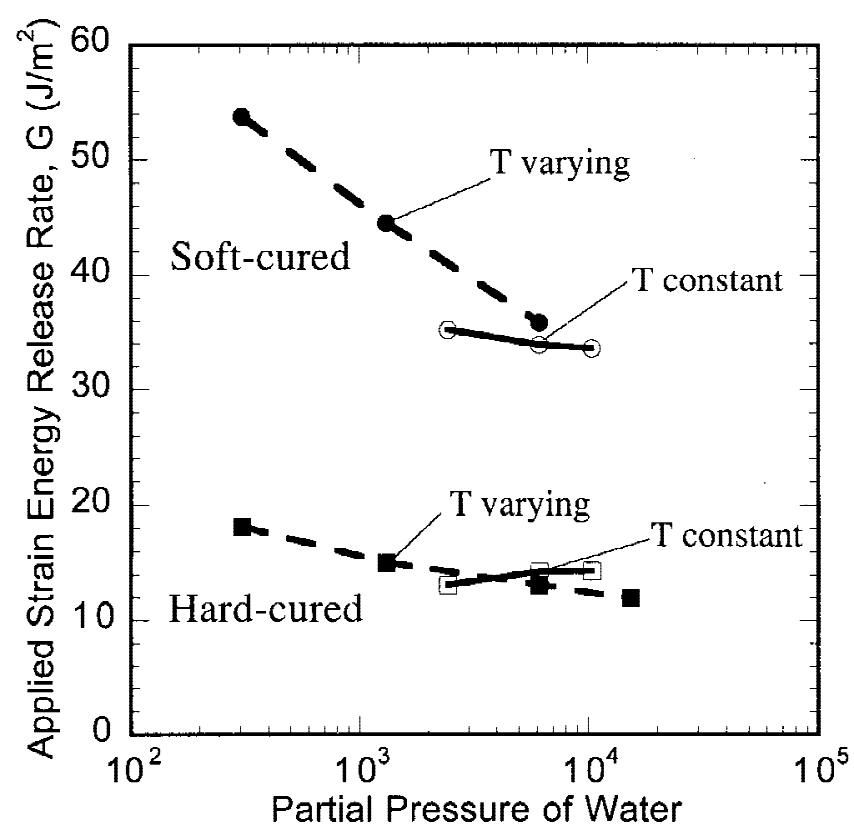

FIG. 14. Effect of the partial pressure of water and temperature on $G$ for both soft- and hard-cured BCB. $G_{\text {applied }}$ was measured at a velocity of $3 \times 10^{-5} \mathrm{~m} / \mathrm{s}$.

should also be noted that in polymer systems, increasing humidity often results in plasticizing effects near the crack tip that relax the crack-tip stress fields and lower subcritical crack-growth rates, as has been reported for bulk PMMA ${ }^{47}$ and polyimide $/ \mathrm{SiO}_{2}$ interfaces. ${ }^{15}$ Clarification of the role of such competing mechanisms for subcritical debonding of interfaces in microelectronic applications is the subject of ongoing study.

\section{CONCLUSIONS}

Adhesion values in the range of $10-60 \mathrm{~J} / \mathrm{m}^{2}$ were obtained for interfaces between benzocyclobutene (BCB) and nitride-passivated silicon wafers. The fracture specimens contained selected epoxy underfill layers that were found to affect adhesion. The adhesion of the $\mathrm{BCB} /$ nitride interface with the amine-terminated adhesion promoter (AP8000) was higher for soft-cured BCB than for hard-cured $\mathrm{BCB}$. In addition, for the hard-cured $\mathrm{BCB}$ specimens, adhesion was also enhanced with the amineterminated adhesion promoter compared to the adhesion promoter with the vinyl-end group (AP3000). Detailed chemical analysis of the debond surfaces confirmed that failure was adhesive between the BCB and nitride; however, the specific failure location with respect to the silane adhesion promoter was found to vary depending on $\mathrm{BCB}$ curing conditions. Adhesion of the $\mathrm{BCB} /$ nitride interface was sensitive to the elastic modulus of adjacent underfill layer. The surprisingly large effect of underfill elastic modulus on $G_{\mathrm{c}}$ values was revealed through fracture energy simulations. 
All of the interfaces studied displayed extensive subcritical debond growth under applied values of $G$ lower than those required to produce catastrophic failure. The temperature dependence of subcritical debond growth was described with a simple thermal activation model. Unlike other inorganic dielectric systems, subcritical debonding of the present $\mathrm{BCB}$ material from the nitride passivation was not sensitive to the activity of the environmental species. Subcritical debond growth has important implications for long term reliability of microelectronic devices.

\section{ACKNOWLEDGMENTS}

This work was funded by SEMATECH Inc. and by the SRC Corp. under Contract PP-458. J.W.H. was supported by the National Science Foundation under Contract NSF-DMR-98-09363, and Y.W. acknowledges support from the Chinese National Science Foundation and the Chinese Academy of Sciences. We are particularly grateful for assistance from Ms. E. Sorongon (Sematech) and Drs. M. Roesch (HP), E. Shaffer and P. Garrou (Dow Chemical), K. Loh (Zymet), and M. Edwards (Dexter).

\section{REFERENCES}

1. C.A. Harper, Electronic Packaging and Interconnection Handbook, 2nd ed. (McGraw Hill, New York, 1996).

2. S-Y. Kook, J.M. Snodgrass, A. Kirtikar, and R.H. Dauskardt, 120, 328 (1998)

3. L.C. Wang, Z. Mei, and R.H. Dauskardt, in Materials Reliability in Microelectronics IX, edited by C.A. Volkert, A.H. Verbruggen, and D.D. Brown (Mater. Res. Soc. Symp. Proc. 563, Warrendale, PA, 1999).

4. C.P. Wong, D.B. Clegg, Ananda H. Kumar, R.A. Kirchhoff, C. Carriere, K. Bruza, N. Rondan, and R. Sammler, Chapter 14: Package Sealing and Encapsulation, in Microelectronics Packaging Handbook Semiconductor Packaging: Part II, edited by R.R. Tummala, E.J. Rymaszewski, and A.G. Klopfenstein (Chapman \& Hall, New York, 1997), Vol. 2.

5. R.H. Dauskardt, M. Lane, Q. Ma and N. Krishna, Eng. Fract. Mech. 61, 141 (1998).

6. K.M. Liechti, S.T. Schapp and J.G. Swadener, Int. J. Fract. 86, 361 (1997)

7. J.R. Rice, J. Appl. Mech. 55, 98 (1988).

8. J.W. Hutchinson and Z. Suo, in Advances in Applied Mechanics, edited by J.W. Hutchinson and T.Y. Wu (Academic Press, Inc., New York, 1992), Vol. 29, pp. 63-191.

9. Q. Ma, J. Bumgarner, H. Fujimoto, M. Lane, and R.H. Dauskardt, in Materials Reliability in Microelectronics VII, edited by J.J. Clement, R.R. Keller, K.S. Krisch, J.E. Sanchez, and Z. Suo (Mater. Res. Soc. Symp. Proc. 473, Pittsburgh, PA, 1997), pp. 3-14.

10. M. Lane, R.H. Dauskardt, R. Ware, Q. Ma and H. Fujimoto, in Materials Reliability in Microelectronics VII, edited by J.J. Clement, R.R. Keller, K.S. Krisch, J.E. Sanchez, and Z. Suo (Mater. Res. Soc. Symp. Proc. 473, Pittsburgh, PA, 1997), pp. 21-26.

11. X. Dai, M.V. Brillhart, and P.S. Ho, in Proc. 48th Electronic Components and Technology Conference, Seattle, WA (IEEE, New York, 1998).
12. M. Lane, M. Lane, A. Vainchtein, H. Gao, and R.H. Dauskardt, J. Mater. Res. (2000, in press).

13. C-A. Dai, E.J. Kramer, J. Washiyama, and C-Y. Hui, Macromolecules 29, 7536 (1996).

14. K.L. Ohashi, A.C. Romero, P.W. McGrowan, W.J. Maloney, and R.H. Dauskardt, J. Orthop. Res. 16, 705 (1998).

15. J.M. Snodgrass, D. Pantelidis, J.C. Bravman, and R.H. Dauskardt, in Low-Dielectric Constant Materials V, edited by J. Hummel, K. Endo, W.W. Loe, M. Mills, and S-Q. Wang (Mater. Res. Soc. Symp. Proc., 565, Warrendale, PA, 2000), pp. 123-128.

16. S-Y. Kook, A. Kirtikar, and R.H. Dauskardt, in Materials Reliability in Microelectronics IX, edited by C.A. Volkert, A.H. Verbruggen, and D.D. Brown (Mater. Res. Soc. Symp. Proc. 563, Warrendale, PA, 1999).

17. J.G. Swadener and K.M. Liechti, J. Appl. Mech. 65, 25 (1988).

18. J.G. Swadener, K.M. Liechti, and A.L. de Lozanne, J. Mech. Phys. Solids 47, 223 (1999).

19. S.M. Wiederhorn, E.R. Fuller, Jr., and R. Thomson, Met. Sci. 14, 450 (1980).

20. S. Bandyopadhyay and H.R. Brown, Polymer 22, 245 (1981).

21. M.K.V. Chan and J.G. Williams, Polymer 24, 234 (1983).

22. M.K.V. Chan and J.G. Williams, Polymer 24(Feb), 234 (1983).

23. K. Tonyali and H.R. Brown, J. Mater. Sci. 21, 3116 (1986).

24. M. Lane, N. Krishna, I. Hashim, and R.H. Dauskardt, J. Mater. Res. 15, 203 (2000).

25. E. Moyer, E. Ritter, M. Bernius, P. Townsend, R. Harris, H. Projanto, and D. Denton, Proc. IEPS 1, 37 (1992).

26. T. Stokich, W. Lee, and R. Peters (Mater. Res. Soc. Symp. Proc. 227, Pittsburgh, PA, 1991), p. 103.

27. R.A. Kirchhoff, et al., J. Macromol. Sci. Chem. A 28(11 \& 12), 1079 (1991).

28. J. Im (personal communication, Dow Chemical Co., Midland, MI, 1999).

29. D.E. Turek, Polym. Eng. Sci. 33, 328 (1993).

30. M.F. Kanninen, Int. J. Fract. 9, 83 (1973).

31. F.E. Penado, J. Compos. Mater. 27, 383 (1993).

32. Zhigang Suo and John W. Hutchinson, Int. J. Fract. 43, 1 (1990).

33. M.D. Thouless, IBM J. Res. Dev. 38, 367 (1994).

34. D. Briggs, Handbook of X-ray and Ultraviolet Photoelectron Spectroscopy (Heyden, London, United Kingdom, Philadelphia, PA, 1977), p. 398.

35. J.W. Hutchinson and A.G. Evans, Acta Mater. 48, 125 (2000).

36. P. Klein and H. Gao, Eng. Fract. Mech. (2000, in press).

37. V. Tvergaard and J.W. Hutchinson, J. Mech. Phys. Solids 41, 1119 (1993).

38. Y. Wei and J.W. Hutchinson, Int. J. Fract. 95, 1 (2000).

39. Z. Li, S. Schmauder, and M. Dong, Comp. Mater. Sci. 15, 11 (1999).

40. J. Qu and C.P. Wong, Proc.-Electron. Compon. Technol. Conf. 848 (1998).

41. D. Maidenberg and R.H. Dauskardt, Stanford University (2000, unpublished results).

42. S.M. Wiederhorn, E.R. Fuller, R. Thomson, Met. Sci. 14, 450 (1980).

43. L. Gero, J. Chem. Phy. 16, 1011 (1948)

44. F. Bueche, J. App. Phys. 26, 1133 (1955).

45. M.K.V. Chan and J.G. Williams, Polymer 24, 234 (1983).

46. M. Lane, Qing Ma, H. Fujimoto, N. Krishna, and R.H. Dauskardt, in Materials Reliability in Microelectronics IX, edited by C.A. Volkert, A.H. Verbruggen, and D.D. Brown (Mater. Res. Soc. Symp. Proc. 563, Warrendale, PA, 1999).

47. N.C. Nguyen, W.J. Maloney and R.H. Dauskardt, J. Mater. Sci.: Mater. Med. 8, 473 (1997).

48. J. Im, E.O. Shaffer, R. Peters, T. Rey, C. Murlick and R.L. Sammler, Proc. ISHM '96, Oct 6-10, Minneapolis, MN, (Microelectronics Society, Reston, VA, 1996), p. 168. 